\title{
SIETE HIPÓTESIS PARA UNA ESTÉTICA DE LA LIBERACIÓN*
}

\author{
ENRIQUe DusSEL \\ Doctor en Filosofía Profesor UAM, Harvard y Colonia \\ https://dx.doi.org/10.12795/astragalo.2018.i24.02
}

Estas hipótesis preliminares para una Estética de la Liberación, sugerida en muchas de mis obras escritas durante los últimos años, quieren ahora ir tomando la fisonomía de una narrativa, de un momento en el sistema abierto de la Filosofía de la Liberación, que llevaría por título tal nombre; es decir Para una Estética de la Liberación, y al mismo tiempo después del giro pertinente Hacia una estética decolonial. Por ser hipótesis me libro de mayores referencias bibliográficas e iré directamente al contenido de la cuestión sin advertencias mayores de posiciones teóricas estéticas clásicas y actuales, para mostrar el núcleo teórico-poiético del asunto.
HIPÓTESIS PRIMERA. LA INTENSIÓN LLAMADA AÍSTHESIS (A"I $\Sigma \Theta H \Sigma I \Sigma)$ Y EL MUNDO ESTÉTICO. LA ONTOLOGÍA ESTÉTICA

Corriendo el riesgo que se me acuse de heleno-centrismo pero con la finalidad de poder así después mejor mostrar una estética descolonizada de liberación, partiré frecuentemente de palabras claves del griego (deberemos encontrar la palabra equivalente en toda cultura vigente, y será tarea futura, con los matices análogamente distintivos de cada una de ellas, igualmente latinoamericana, azteca, maya, quechua, aymara, etcétera). Así por ejemplo, la primera de ellas se situará como el punto de partida ontológico de toda estética posible.

\footnotetext{
* Conferencia dictada en agosto de 2017 en la Facultad de Artes de la Universidad Nacional de Chile. Pudo tener por título Hacia una estética decolonial, indicando el primer momento fuerte de la negatividad: la negación de la realidad de una estética ocultada bajo el manto de la colonialidad eurocéntrica-occidental de la estética imperante actual.
} 
Se trata de la apertura, la posición (Einstellung diría Husserl) primera, la facultad que des-cubre los fenómenos originarios de lo que llamaremos belleza, cuestión por demás ardua y que en el presente se pasa frecuentemente por alto para no entrar en equívocos que impedirían temas más urgentes y disputados en el presente cultural y estético.

Dicha posición de apertura de la subjetividad humana ante las cosas reales que

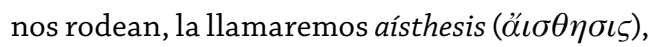
palabra de la que deriva en castellano estética, $\mathrm{y}$ no arte (de origen latino, ars, y que significa más bien tékhne en griego).

Nos ocuparemos entonces de una estética que se compondrá del momento ontológico de la aísthesis y del momento óntico o expresivo-productivo de la obra de arte (que se referirá a la poiética, de poíesis en griego).

Empecemos entonces por el origen ontológico de la estética: ¿Qué es la aísthesis? El ser humano es un ser-en-el-mundo ${ }^{1}$ inevitablemente. Se sitúa así el ser humano ante las cosas reales (FL 2.2.2) $)^{2}$ del mundo, los fenómenos, implicados por distintas maneras de afectar la subjetividad mundana del que vive dicho mundo.

Esa presencia, afecta a la subjetividad en su sensitividad-inteligente o en su inteligencia-

1 Heidegger habla del in-der-Welt-sein (ser-en-el-mundo). Rodolfo Kush, filósofo argentino alumno de Carlos Astrada, que reflexiona sobre la ontología de los pueblos originarios, explora la diferencia del castellano entre estar y ser. Adoptamos todavía en este caso, sin embargo, ser pero como una posición ontológica que expresa permanencia y espacialidad (como el estar castellano).

2 Citaremos como FL mi obra Filosofía de la liberación [1975], FCE, México, 2011 (en Web-page www.enriquedussel.com/ obras). Refiero a este libro por su carácter sistemático categorial de la Filosofía de la Liberación. sensitiva ${ }^{3}$, unitaria e inseparablemente. Es racional $^{4}$, emotiva ${ }^{5}$, perceptual ${ }^{6}$, sensible, estética simultáneamente. Puede llamarse dicha apertura que afecta la corporalidad unitaria humana una comprensión del ser del mundo que es simultáneo a un querer-vivir-en-el-mundo.

La aísthesis es la apertura al mundo descubierto como bello (no solo su interpretación, su querer volitivo, su presencia sensible, etcétera), y de las cosas reales (o imaginarias) del mundo como manifestando su belleza. Es una facultad que comprende cognitivamente $y$ desea como voluntad-de-vida, unidad emotivointelectual. Es la apertura estética al mundo y a las cosas.

Debe distinguirse esta apertura o facultad de otras facultades expuestas en las estéticas clásicas. No nos referimos al campo de la teoría ( $\zeta \varepsilon \omega \varrho i ́ \alpha)$, al de las acciones prácticas ( $₫ \varrho \alpha \xi i ́ \varsigma)$ y a las productivas o poiética

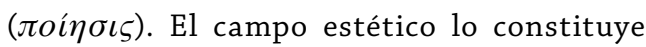
entonces la aísthesis, que es una facultad compleja que implica momentos o aspectos de los otros campos pero que los redefine desde una posición o actitud propia y distinta, como apertura estética al mundo. Veamos por partes.

3 Propuesta metafísica de X. Zubiri. Ver X. Zubiri, Sobre el sentimiento y la volición, Alianza, Madrid, 1993.

4 Los neurólogos denominan el neocortex principalmente, como la referencia principal de estas actividades.

5 Se denomina el sistema límbico al ámbito de la afectividad, emotividad, evaluación, etcétera. La música del cerebro, vista desde la neurociencia, consta de miles de millones de notas musicales cuya combinaciones son infinitas, 86 mil millones de enronas. Lo más refinado sucede en la región más vieja, la más agreste, rudimentaria, básica. La zona límbica; en ¿Cómo escucha música nuestro cerebro?, en Revista de la Universidad, UNAM (México), p.127 y ss.

$6 \mathrm{M}$. Merleau-Ponty describe la unidad de estas funciones en la percepción que se compone de múltiples relaciones entre estos subsistemas cerebrales. 
La teoría (theoría) representa a las cosas reales en el neocortex cerebral principalmente, actualizando lo real neuronalmente (intencionalmente diría la fenomenología). Es la captación de la cosa real por parte del sujeto cuya finalidad última es sin embargo usarla a fin de afirmar la vida del sujeto.

La praxis (práxis) es en cambio la posición del sujeto ante acciones o instituciones posibles con respecto a los otros seres humanos. Cuestiones que son tratadas por la ética, la política, la economía, etcétera.

La poíesis tenía un contenido ambiguo, ya que por una parte puede ser considerada como técnica (y recordando que entre los griegos un escultor, un arquitecto, o un pintor no se distinguían como oficio de los artesanos). Aunque los poetas o los autores de las tragedias eran considerado con mayor aprecio pero no se distinguían esencialmente de dichos artesanos.

La técnica ( $\tau \varepsilon ́ \chi v \eta$, tékhne) propiamente dicha se ocupa más bien de la relación del sujeto con la naturaleza, creando instrumentos culturales para transformar dicha naturaleza en cultura, es decir en una morada adecuada para el ser humano.

Por su parte, la aísthesis se la sitúa frecuentemente en el nivel de la poíesis ya nombrada pero no meramente como técnica (o ars en latín). Ahora debemos distinguirla claramente como una facultad o apertura propia de lo que llamaremos estética. El no haberla distinguido de las otras facultades dificulta la descripción del fenómeno de la belleza que en primera instancia ${ }^{7}$, era considerada un momento constitutivo de la cosa real. Se confundían las propiedades físicas de las cosas con la belleza que se

7 Es la posición de X. Zubiri. constituye solamente en el horizonte del mundo. Veamos la cuestión más precisamente.

En la economía política por ejemplo, se confunde frecuentemente las propiedades físicas (naturales) de las cosas reales (de una manzana por ejemplo) con el valor de uso (la manzana como comestible, como útil; como la utilidad alimenticia).

Si no hubiera seres vivos, sean animales o humanos (con hambre, porque la vida consume energía y materia y debe recuperarlas comiendo), nunca aparecería ninguna cosa real como comestible, es decir como satisfactor de una necesidad (porque sin vida animal o humana no hay necesidades).

El valor de uso de una cosa real se constituye desde la necesidad del viviente, a partir de las propiedades físicas que se manifiestan como útiles, comestibles en este caso, para la vida. La cosa real es ahora una mediación para la vida. El valor de uso tiene una referencia a la cosa física como portadora material de un valor de uso constituido como mediación desde la necesidad de la subjetividad humana como corporalidad viviente. Sin subjetividad viviente no hay valor de uso; con la sola necesidad subjetiva no se crea el valor de uso si no hay una propiedad física real que lo sustente, que la porte.

Es la existencia misma y actual de la relación entre la necesidad del viviente y las propiedades físicas de la cosa real lo que da origen al valor de uso de la cosa. ¿El valor es subjetivo u objetivo? Ambigua pregunta. No es meramente subjetivo ni meramente objetivo. ¡Es la relación misma de la subjetividad en referencia a la objetividad! Si se toma cada término de la relación separadamente (sujeto sin relación con la cosa real, o cosa real sin 
relación con el sujeto) no hay valor de uso. Solo existe realmente en la relación en acto. De igual manera en la estética.

La aísthesis es subjetivamente la que constituye objetivamente a las cosas reales aquello que se denomina belleza o valor estético (lo llamaremos así provisoriamente) que no es ni mera existencia subjetiva ni tampoco solo una propiedad física de la cosa $\mathrm{real}^{8}$.

Esto acontece porque la belleza es un fenómeno que se refiere a propiedades físicas de las cosas reales, es decir, que es parte del cosmos (FL 2.2.3), pero que se manifiesta fenomenológicamente con sentido al ser subsumido en el mundo, cuya totalidad es el campo estético, es decir como un momento cósmico dentro del mundo.

La aisthesis es la facultad subjetiva que constituye a la cosa real desde el criterio de la afirmación de la vida del observador de la cosa real en tanto es inteligida sensible y emotivamente (el momento de la fricción o alegría) de aquello que se manifiesta en el mundo (en tanto fenómeno mundano) como poseyendo propiedades reales que hacen posible la afirmación de la vida. Es un modo de presencia de la cosa real ligada a la posibilidad del sujeto de seguir viviendo plenamente.

El canto del gallo, y obsérvese que es un canto en el cuasi-mundo del animal ${ }^{9}$ que

$\mathbf{8}$ Nuevamente queremos insistir en que Zubiri atribuye la belleza a la realidad misma en cuanto tal.

9 Heidegger habla del Weltarm de los animales (Die Grundbegriffe der Metaphysik. Welt-Endlichkeit-Einsamkeit [Klostermann, Frankfurt, 2010], II, 3, pp.294ss). A diferencia del animal el ser humano es constituyente del mundo (der Mensch ist weltbildend) (p.397 y ss). Y aclara que la constitución del mundo (Weltbildung) [es] el acontecer fundamental del Dasein (p.507 y ss). La noción de Bildung es de difícil traducción al castellano. Lo interesante es que Heidegger parte ya del ser animal como anticipo presagia en el presente y futuro el mundo pleno del ser humano y que se expresa como el canto de los campesinos del río Rhin festejando la cosecha del alimento gozoso de la vid que se transformará en vino (disponiblidad embriagante para vivir más felizmente la vida), que inspiró a L. Beethoven y que desarrolló en su Quinta Sinfonía en el Canto de la Alegría. ${ }^{10}$

La música, las obras del arte que modulan el sonido (hasta una obra sinfónica de decenas de instrumentos y cientos de participantes de la orquesta y el coro) es el desarrollo de la poíesis.

Desde el canto del gallo que es cuasimundano, se trata ya de la expresión de la existencia de la facultad que denominamos aísthesis. El gallo ante la belleza de la aurora expresa en el canto la alegría de la celebración de la belleza físico natural como momento de la presencia de la disponibilidad de lo real para la vida animal. Descubre (y constituye) la salida del sol como bella, en tanto la aurora, la luz del sol, los colores del firmamento, todo ese panorama que vence la noche (la muerte) es constituido por el sujeto en su mundo como algo bello.

Hay entonces dos momento de la belleza: la alegría ante la aurora misma y el canto (ya veremos más adelante esta cuestión donde la estética se bifurca). La contemplación-emotiva, como fruición subjetiva es la aísthesis, en cierta

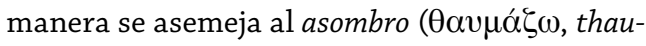
máso) como pathos entusiasta que se situaba en el origen de la filosofía para Aristóteles.

del ser humano. Hay que desarrollar estas intuiciones en la estética.

10 Es un ejemplo eurocéntrico pero que indica de todos modos el origen popular de esa magnífica expresión de belleza. 
Es un asombro, un pasmo, una alegría ante lo real como mediación, como posibilitante del seguir viviendo, es decir, del vivir mismo.

El descubrimiento de la cosa real como mediación para la realización de la vida es lo que llamamos el descubrimiento de la disponibilidad o belleza. Los colores, el perfume, el sonido, la textura, su contenido sustantivo, la proporción adecuada de las propiedades físicas a la corporalidad humana y sus necesidades (desde el estómago hasta la fantasía diría Marx) son subsumidas en el mundo y semióticamente interpretadas como mediaciones para la vida. La belleza de la cosa real (o imaginada) es la síntesis constituida por la aísthesis de esa mera cosa física real.

La bella flor que produce la vida vegetal tiene colores (desde hace unos 400 millones de años entre los vegetales) y perfumes (para atraer a los insectos que casi con igual antigüedad las fecundan y de donde se alimentan). Los insectos (en su proto-estética) puedan descifrar gracias a la belleza de la flor (en un acto de una proto-hermenéutica todavía no humana), la disponibilidad del néctar necesario para la vida del insecto; que al mismo tiempo es la manera por la que los vegetales pueden reproducirse para perpetuar la vida dela especie.

La flor, órgano sexual, por su belleza afirma la vida. La belleza de la flor es entonces un fenómeno esencial para la vida. Por ello Katya Mandoki ${ }^{11}$ sitúa a la estética dentro del horizonte de la vida y como un momento de la vida misma para permanecer, evolucionar y diseminarse.

El ejemplo magníficamente descrito del pavo real, desde las observaciones de Charles Darwin, son ciertamente ejemplares.

11 Katya Mandoki, El indispensable exceso de la estética, Siglo XXI, México, 2013.
El descubridor de la evolución de las especies llegó a expresar que la belleza es un medio privilegiado de la misma evolución. El plumaje desplegado del pavo real macho para atraer a la hembra pone a la belleza como medio para que se elija lo más desarrollado de una especie como criterio de elección en vista de la evolución de las especies.

El bello canto del pájaro no tiene otra finalidad que igualmente, seducir a la hembra que elige al que canta con mayor belleza; es decir, el que expresa mayor vitalidad en el desarrollo de la especie, para generalizar en la descendencia esa mayor plenitud de la vida, expresada en la belleza en su canto. Se trata de un darwinismo estético (que nada tiene que ver con el darwinismo por selección competitiva agresivo y destructora).

La Estética de la Liberación es ante todo la interpretación de toda la estética desde el criterio de la vida (como belleza o bio-estética) y de la muerte (como criterio de la fealdad o necro-estética)).

Si indagamos con mayor precisión, el sujeto humano representa a la cosa como un objeto (a la manera zubiriana) y en un segundo momento ese sujeto se pone en el mundo como extático, como admirador de lo maravilloso, como entusiasmado gracias a un sentimientointeligente o una inteligencia-emotiva, que hemos llamado aísthesis, que es una intensión fenomenológica precisa (piénsese en Husserl) que constituye ${ }^{12}$ al objeto con un sentido

12 La constitución (Konstitution) es un momento o acto preciso descrito en la fenomenología. El objeto (Gegenstand; la cosa real representada actualmente en el cerebro, en el sentido de X. Zubiri) se la determina con un cierto sentido (Sinn) correlativa a la intensión. F. Frege distinguía entre significación (contenido semántico del objeto) y sentido (FL 2.3.5; el valor estético en este caso) sin descubrir 
particular: como bello; constituye el valor estético como dando existencia a la experiencia estética en la relación del sujeto/aísthesis ante el objeto/bello ${ }^{13}$; es repito, el valor que aparece en la cosa real/objeto).

Repitiendo. La cosa real es un momento del cosmos que puede ser subsumida en el mundo. Es decir, las propiedades físicas de la aurora o salida del sol es un hecho real; en cuanto hecho es ya mundano ${ }^{14}$ para un sujeto y como objeto de la experiencia. Ese objeto es ahora a su vez, y como segundo momento, constituido desde la

todas sus implicaciones. Si la intensión es erótica el objeto adquiere el sentido sexual; si es económica se determina el valor económico del objeto; si es político se manifiesta el objeto como una mediación en el ejercicio del poder (valor político), etcétera. En el nivel cognitivo Husserl hablaba de la noesis (intensión cognitiva) y el noema (el sentido o contenido noético del objeto). M. Heidegger puede así distinguir el ser-en-el-mundo como posición originaria del ser humano (el Dasein), del momento fenomenológico de ponerse en el mundo constituyendo las cosas del mundo en un cierto sentido es decir, como ego cogito cogitatum (las cosas pensadas por un pensador o como lo sentido por el que siente, como cogitatio), que para Antonio Damasio es un feeling (sentir). La aísthesis es igualmente un modo segundo del ser-en-el-mundo fundamental; es el abrirse o constituir un sentido particular, es decir, abrirse estéticamente (no cognitiva, ética o políticamente) al mundo.

13 Lo bello del objeto podría denominarse en griego como

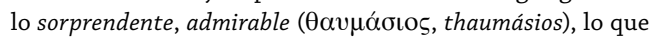
entusiasta gozosamente por su disponibilidad para la vida. Lo que porta el valor de la belleza.

14 Para L. Wittgenstein, en 1.1; Die Welt ist die Gesamtheit der Tatsachen, nicht der Dinge (El mundo es la totalidad de los hechos, no de las cosas) (Tractatus Logico-Philosophicus, Routledge and Kegan Paul, New York, 1969, p.6). Es decir, el hecho (Tatsachen) es ya mundano y se refiere a la cosa (Dinge), pero no es la cosa en tanto cosa, sino la cosa en tanto hecho empírico en el mundo. El hecho es la cosa conocida, amada, que causa asombro, etcétera (no es la cosa en sí ignota de Kant). La cosa en sí ignota es simplemente las cosas del cosmos que el ser humano no ha hecho objeto de su conocimiento; es decir, son las cosas cósmicas que no han sido subsumidas en un mundo; o con Zubiri, o los objetos del mundo como cosas del cosmos en cuanto de suyo. intensión estética (aísthesis) en el sentido de lo bello, como valor estético, siendo ese sentido lo constituido por la posición fenomenológica del sujeto ante el objeto que es interpretado como disponible para la vida, lo que causa en el sujeto una admiración entusiasta, una alegría por el hecho de poder seguir viviendo, un descubrimiento de una mediación que puede ser empuñada para lograr el fin de la vida. Esa posición subjetiva fenomenológica constituye a las cosas reales como bellas.

La belleza es la presencia, la patencia de esa experiencia originaria llamada estética. Las propiedad físico-cósmicas son el fundamento material de tal experiencia (las propiedades deben ajustarse a posibilitar la vida en su contenido, relaciones, posibilidades semánticas de su descubrimiento (y para ello el color, el gusto, el sonido, el perfume, etcétera) que debe guardar una armonía con las posibilidades limitadas de la actualización de ellas en el interior de la corporalidad humana, en cuanto al posible acceso a esas disponibilidades reales.

La belleza así descrita la denominaremos en una primera instancia, como belleza física o natural, la de la aurora que hasta el gallo canta en su sentir-cognitivo o conocimientoemotivo animal, y que le lleva a manifestar como expresión de esa belleza descubierta, un signo externo que usa el sonido que se ejerce para producir un sistema de comunicación por medio de una mediación, un signo, una obra que llamamos canto del gallo. No es lo mismo la aisthesis animal que la obra llamada canto. Por ahora y en primer lugar, se trata de la constitución de una belleza o estética física o natural, situada como mero hecho en el mundo (y aun en el cuasi-mundo animal, como diría Heidegger), sin describir todavía la produc- 
ción de signos u obra alguna. El mero hecho natural, primigenio. La belleza constituida por el observador del arroyo en la montaña que susurra (un sonido) en la caída del agua pura de roca en roca; ese sonido es una propiedad física captada por la aísthesis como bella. Dada ahí, sin todavía ninguna transformación humana cultural.

\section{HIPÓTESIS SEGUNDA. LA PLURALIDAD ANALÓGICA DE LA AÍSTHESIS Y POR ELLO DE LOS CAMPOS ESTÉTICOS}

Demos ahora un paso más en la descripción del tema que nos tiene ocupados. Ese pasmo o tono (diría nuevamente X. Zubiri) ante lo real como mediación universal para la realización de la vida, esa belleza física o natural, se manifiesta a través de múltiples aspectos de la cosa real; como distintas aperturas, modos de presentarse de la cosa real que enfrenta a la subjetividad determinada por la intensión estética (es decir, de la aísthesis). En cuanto el cosmos se manifiesta en el mundo como mediación universal para la vida, en cuanto bello entonces, debe contar con tipos de manifestación o aparición fenoménica que permitan al sujeto estético (aísthesis) acceder a la realidad de lo real en su belleza.

Es decir, advertir en la manzana por su forma, su color, su gusto que es una manzana y no una piedra; por presentarse como apetitosa y no como lo que causa nausea; por su perfume que es deleitoso y no como cuando la manzana se pudre que produce asco, fealdad entonces; por su momento de plenitud nutritiva apropiada para ser consumida (es decir, por su madurez o disponibilidad a punto para ser digerida), etcétera.
Es decir se constata semióticamente (descubriendo hermenéuticamente) su contenido, y probándose se verifica ser efectivamente un cosa disponible o una mediación posible actual para la vida. ${ }^{15}$ Es por todos estos aspectos o dimensiones de la belleza que el pavo real despierta la aísthesis de la hembra, que juega como el resorte en la hembra en la elección del macho para tener la mejor cría en el desarrollo de la especie viviente.

Denominamos la pluralidad analógica de la aísthesis los distintos campos estéticos que se constituyen desde esa diversidad de accesos posibles desde la subjetividad (de una cierta intensión) co-determinada por las propiedades físicas de la cosa real (de su estatuto cósico).

El concepto de campo ${ }^{16}$ ya lo hemos analizado en otras obras. Apliquémoslo ahora a la estética. Debe tenerse primeramente en cuenta el concepto de mundo, como totalidad ontológica ( $F L$ 2.2), cuya definición vale analógicamente a sub-mundos particulares, sabiendo que un sub-mundo es un mundo como parte existencial del mundo en su sentido indicado. Cuando se habla de mundo estético se hace referencia al sub-mundo estético de lo cotidiano (óntico) dentro del mundo en general (en sentido ontológico). El mundo estético,

15 Pero a diferencia del mero valor de uso es ahora constituido universalmente como valor en cuanto bello en cuanto se constatan las condiciones múltiples para que la vida sea posible. Es la vida la que ilumina, si vale la metáfora, todas las cosas (no en su particularidad) en cuanto universalmente situadas como medios para el fin: la experiencia de estar viviendo; la alegría de poder vivir; la síntesis de todas las experiencias de la vida en cuanto posibilitante de esa vida.

16 Véase mi obra 20 tesis de política, 1.2. Piénsese analógicamente todo lo que ahí se describe como campo político al campo estético, atendiendo a la distinción propia de cada campo. 
tomado como parte del mundo en general, queda definido desde el horizonte de la belleza (del ser como bello) y de todos los entes que lo componen en tanto bellos, constituidos por la subjetividad determinada por la intensión estética de la aísthesis.

El campo estético es, tomado abstractamente, una totalidad ontológica de todo aquello que lo compone. Así un árbol es en dicho campo considerado desde la belleza: un árbol bello. Si lo considero desde el campo económico puede ser un árbol muy caro (en su precio), o en el campo tecnológico de buena madera para hacer un mueble. El distinto sentido de los entes lo determina el horizonte ontológico respectivo. En el campo estético los entes serán bellos o sin valor estético: feos. Forman por su parte una totalidad sistémica como veremos (en el caso de una cultura) pero deseamos indicar por ahora otro aspecto. La distinción por su contenido o por la constitución del campo desde un aspecto de las múltiples manifestaciones fenomenológicas de la cosa bella.

No es lo mismo la propiedad física del color que del sonido o del perfume. Son propiedades físicas distintas en la cosa real y también son aperturas de la subjetividad distintas por las que se construye neuronal o subjetivamente la cosa real en la subjetividad humana (intensional, neuronal). El componer neuronal o intensional de la cosa real en la representación subjetiva tiene diferentes componentes. Se sintetiza en el concepto la cosa real subjetivamente gracias a la percepción, que tiene componentes de color, sonidos, gusto, perfume, tamaño, forma, etcétera. Todo ello constituye una totalidad como percepción inescindible que Merleau-Ponty expuso en La fenomenología de la percepción.
De esta manera podemos concluir que cada una de esas cualidades de la cosa constituye por su parte sub-campos diversos. Así podemos hablar de un campo visual del color y la forma, del campo auditivo del sonido, del campo del olfato, y otros muchos campos (o subcampos). La estética podrá así especializarse en estos diversos campos (o sub-campos) de las cosas reales en cuando bella. La belleza del color, del perfume, del sonido, etcétera. Estos campos determinan diversas posiciones de la áisthesis.

El color permite descubrir a la flor; si todo tuviera el mismo color no habría ninguna diferenciación entre las cosas reales y la vida no sería posible ya que no podría descubrir el significado y sentido de todas las mediaciones de la vida. La diferenciación de los colores permite semántica o hermenéuticamente descubrir el significado de las cosas reales y la finalidad (en función de la vida) de esas cosas reales. Los colores más significativos de las flores son más rápida y claramente discernidos por los insectos. Lo mismo con los sonidos, los perfumes, etcétera.

La estética física o natural se admira ante el esplendor de las propiedades física de las cosas reales en tanto más adecuadamente permite recortar o descubrir las cosas desde el magna indiferenciable de lo no constatable por su diferencia. El color rojo de la rosa permite descubrirla de entre las cosas reales en su conjunto. El color juega semánticamente una función esencial en el discernimiento de la mediación necesaria. Lo mismo el sonido, el perfume, la consistencia, la forma, el movimiento, etcétera.

Es así que la estética se distinguirá en diversos campos (sub-campos entonces) según sea aquel aspecto o determinación de la cosa real 
que se toma principalmente en consideración. Nace así la exigencia de distinguir el campo estético en general de los sub-campos estéticos, tales como el sub-campo del color (que se desarrollará como la pintura), del sonido (que se desarrollará como la música), de la movilidad significativa del cuerpo humano (como la danza), del mero habitar en cavernas (como la arquitectura), del signo comunicativo (hasta la literatura), etcétera, que para simplificar indicaremos directamente como el campo de la pintura, de la música, etcétera (eliminando el sub-cacofónico).

Como puede observarse hemos pasado de la llamada belleza física o natural a la belleza propiamente humana, antecedida por la belleza animal (del mundo animal que Heidegger denomina Weltarm: un mundo todavía pobre). El canto del gallo ante la aurora es el inicio de un proceso que culmina en el canto cultural del ser humano desde las primeras comunidades del homo sapiens. ${ }^{17}$

De esta manera hemos situado, no analizado y menos agotado, la descripción de los diversos campos de la estética, los cuales tienen mucho en semejanza (la similitudo de la analogía) y también de distinción (la distinctio), que es lo que propiamente se describe como la tarea propia de las estéticas empíricas (y por supuesto las teorías o comprensiones general

17 No se nos acuse de antropocéntricos, porque el ser humano no es producto del ser humano sino del proceso evolutivo de la vida en el planeta Tierra. Es un fruto de la Tierra, que metafórica (y como metáfora con sentido) es nuestra Madre. El esplendor y dignidad de la vida humana no es un fruto humano (ni antropocéntrico) sino el reconocimiento de un fruto de la naturaleza. La vida humana es un triunfo de la vida, y considerarla como el fruto mayor del universo no es antropocentrismo, sino responsabilidad de no destruir esa gloria del universo que es el ser humano. o filosóficas de cada uno de estos campos). Por la brevedad de este artículo no entramos aquí en la descripción sistemática de los distintos campos (o sub-campos) de la estética). Ésta sería una tarea propia de los institutos, escuelas o facultades de artes. Aquí nos mantenemos en un nivel ontológico y no propiamente óntico.

En resumen, los diversos aspectos de la estética física o natural (forma, color, sonido, perfume, etc.) se desarrollan en una estética cultural que partiendo de la propiedad física subsumida como bella en el mundo, la despliega constituyendo un fenómeno humano donde la belleza alcanza nuevos modos de su manifestación. Del mero habitar la caverna, donde se utilizan las obras de la naturaleza se desarrolla culturalmente como hogar o casa construido como arquitectura; el mero comer se convierte en el arte culinario; el sonido de las cosas y el canto de los animales se componen como canciones o como música; el simple olor de las cosas como el arte perfumario producido culturalmente ${ }^{18}$; el desplazarse en el espacio, como el caminar o correr como deporte; el movimiento del cuerpo se expresa ahora en la alegría cultural como danza; los signos comunicativos se desarrollan como lenguaje, como escritura, como poesía, como literatura; la mera copulación animal, que sin embargo tiene sus reglas propia, se efectúa como el rito del arte amatorio

18 En una estadía en Egipto, habiendo entrado en un comercio donde se exponían perfumes, nos hicieron arremangar la camisa y con un algodón fueron pasando desde la mano y por todo el antebrazo, depositando sobre la piel el artesano veinte o treinta diversos perfumes. Aquello era una experiencia nunca vivida por el olfato de deliciosos y desconocidos perfumes. Entonces comprendí el desarrollo de la cultura sofisticada del antiguo Egipto que ante el calor sudoroso del desierto inventó el arte perfumario, que ciertamente esgrimió Cleopatra para seducir a los bárbaros romanos. 
erótico cultural (descrito en algún libro sagrado de la India); etcétera. La estética natural se transforma en la estética cultural, humana, histórica, que desarrolla al infinito, en los diversos campos (o sub-campos) estéticos, las primeras y fundantes (ontológicas) experiencias de la aísthesis que hemos denominado estética físico natural en la compleja creación de la aísthesis cultural, ahora cultivada distintamente en cada campo (o sub-campo) estético.

\section{HIPÓTESIS TERCERA. DE LA AÍSTHESIS A LA POÍESIS [ПO'IH II ]]): LA OBRA DE ARTE.}

En efecto el simple hecho de que la aísthesis es ejercida como una experiencia en el mundo (humano, lo que es una redundancia) determina inevitablemente la escisión o distinción entre (a) el mero ser en el mundo ante las cosas reales como entes con sentido (y por ello como bellos o no) dados al uso meramente como naturaleza (FL 4.1.1) o (b) dados como cosas reales modificadas por la producción, por el trabajo, por la intervención transformadora del humano.

De esta manera se pasa de una experiencia de la naturaleza como tal a la naturaleza transformada en cultura (FL 4.2$4.3)^{19}$. Es la humanización de la naturaleza (de la que habla Marx). Aparecen de pronto (anticipado por los animales) objetos producidos por el trabajo humano que comienzan a ser como una nueva esfera en la Tierra, la noosfera crea una esfera cultural (física, material y simbólica) propia del mundo como totalidad de

19 Sobre la cultura véase mi obra Filosofía de la cultura y Transmodernidad, Universidad Autónoma de la Ciudad de México, 2015 (puede consultarse en www.enriquedussel. com/obras). sentido (no como mera realidad cósmica, que es subsumida en la materialidad física de los entes ${ }^{20}$ culturales).

La intervención trans-formadora (el cambiar [trans-] físicamente la forma de las cosas naturales en cosas con sentido o culturales, arte-factos ) abre entonces un nuevo horizonte propiamente inexistente antes de la aparición del ser humano. Hemos definido a la cultura siguiendo en parte a Paul Ricoeur, como La cultura es el conjunto orgánico de comportamientos predeterminados por actitudes (ethos) ante los instrumentos de la civilización (arte-factos) cuyo contenido teleológico está constituido por valores y simbolos de la comunidad, es decir, estilos de vida que se manifiestan en obras de cultura que transforman el ámbito físico-natural en un mundo, un mundo cultural. ${ }^{21}$

En esa totalidad cultural la estética juega un papel fundamental. No solo por el estilo del gusto de la aísthesis, y en este sentido no individualista (contra Kant puede decirse que el gusto o la aísthesis es un ejercicio comunitario y cultural del asombro estético ante la disponibilidad para la vida), se impone de alguna manera a la totalidad de los miembros de una cultura. La estética de la cultura de la India es claramente distinta (con distinción analógica) de la Azteca o la Bantú. La aísthesis es determinada culturalmente como puede observarse en una historia mundial (no eurocéntrica) de la estética de las culturas. Pero si subjetivamente la aisthesis determina un gusto o preferencia en el juicio

20 Véase la diferencia entre cosa, ente y sentido en FL 2.3.8.

21 Para una filosofía de la cultura [1966], en Filosofía de la culturay Transmodernidad, Universidad Autónoma de la Ciudad de México, México, 215, p. 158. 
de las cosas como bellas (y su contrario) ${ }^{22}$ ahora aparece de parte de la realidad cósicacultural (objetivamente, pero no en un sentido kantiano) gracias a las obras de arte (expresión ahora de etimología latina).

$Y$ bien, debemos distinguir entonces

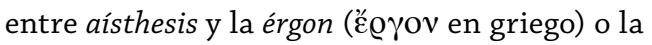
opera/opus (en latín); es decir, entre (a) el acto que abre el mundo estético y (b) la producción (poíesis) de la obra llamada de arte (es decir, puesta en la existencia desde la áisthesis) que es una cosa real o instrumento con sentido dentro del campo estético.

En un trabajo anterior hablé de la filosofía de la póiesis y era en efecto la filosofía de la producción en general, de los instrumentos diseñados, pero no habiendo suficientemente aclarado el momento de la aísthesis y por ello la cuestión de la belleza quedó ambiguamente expuesta. Ahora podemos hablar de una estética como la experiencia ontológica de la aísthesis, y de la totalidad óntica de las obras o creaciones del arte.

Aparece entonces un nuevo tema: la relación de la estética con la técnica (tékhne en griego, y ars en latín, de donde procede la palabra arte en castellano). El arte es una técnica (tékhne), pero una técnica muy especial en tanto el artesano o el tecnólogo (por ejemplo, el albañil y el ingeniero) son solamente técnicos en la actualidad, sin el componente estético en su acto productivo o simplemente trabajo. En las culturas clásicas el técnico era simultáneamente un artista. Fidias era un artesano-artista esculpiendo figuras para el Partenón (de nuevo un ejemplo helenocéntrico).

22 Siendo los genios no un surgimiento solipsista sino más bien la culminación singular dentro de parámentros comunitarios.
Mientras que el artista moderno se diferenció del mero técnico (artesano o tecnólogo) y se definió solamente como el productor de obras de arte y no de otras obras artesanales o tecnológica no estéticas. Nace así la expresión del arte por el arte, con autonomías absoluta de otro campo de actividad humana. Esto dificulta la aclaración de los conceptos. Por ello nos situaremos en el presente y reflexionaremos sobre la distinción entre aísthesis y obra de arte propiamente dicha ${ }^{23}$ pero también en relación con otros campos (cuestión que trataremos en las siguientes hipótesis).

La obra de arte supone la aísthesis pero contiene también otros supuestos. Se trata de desarrollar los momentos de la estética natural, por ejemplo: el sonido y el canto del pájaro, ahora como obra de arte, como música. Para ello se necesitarán instrumentos culturales que habrán de ser creados para poder obtener nuevos sonidos, sonidos más complejos, armonías no naturales, en fin todos aquellos componentes de la música que produzcan como resultado también un crecimiento de la aisthesis y que se vayan depositando como momentos significativos y materiales (como cosas reales creadas) de la cultura. No es de igual grado de desarrollo el canto de un pájaro al conjunto musicalizado de la obra sonora de una orquesta moderna.

23 Aunque la cuestión se complica por lo intervención del diseño (artístico) en la producción de todos los instrumentos a la mano en la civilización contemporánea. Un cuchillo es técnicamente producido por ingenieros pero diseñado al mismo tiempo por diseñadores. El diseñador subsume la técnica del ingeniero en el mundo estético produciendo un cuchillo bello (estéticamente) y eficiente (técnicamente). Sería la presencia del mundo estético que subsume el mero mundo tecnológico. Véase FL 4.3. En esta Filosofía de la Liberación se describió más el diseño que la estética. Estas siete hipótesis completan ese texto antiguo. 
Es posible que el tambor (como lo propone Alejo Carpentier en Pasos perdidos) pudiera ser el primer instrumento cultural que lograra un nuevo sonido musical, es decir cultural, en la historia de la música. El África oriental es ciertamente el lugar del origen del homo, y del homo sapiens. La rudimentalidad del tambor en cuanto instrumento, habla de una simplicidad en la que lo natural ha pasado a ser cultura casi sin modificación formal mayor de esa mediación producida ex profeso. Sin embargo, la potencialidad estética de ese tan simple instrumento conmueve profundamente al ser humano, junto al ritmo, al relato cultural y mítico que lo acompaña, a la danza y a tantos otros componentes como evento de celebración humana donde el tambor es solo un momento que expresa como música un sentido estético pleno, profundo.

Aquí no podemos entrar en toda la complejidad empírica de esta cuestión. Solamente queremos indicar que la obra de arte es el fruto cultural, histórico del crecimiento de la aísthesis, tanto en el productor de la música como del que oye y participa en la obra conmovido (es decir, activando en su subjetividad la experiencia de su propia aísthesis del escucha o espectador).

En la obra de arte no hay solo un productor de un ente estético que desarrolla la mera estética natural, sino que hay una comunidad, una historia cultural, también como determinación determinante determinada por todo el sistema contextual de instrumentos civilizatorios que permiten ese desarrollo. La belleza es crecientemente una nota de todo producto cultural. El campo estético va extendiéndose y penetrando en todos los campos de la existencia humana.
De tal manera que la mutua determinación de la estética y la técnica, la aísthesis y la la poíesis nos permiten descubrir las dos caras de la estética; ni solo el impacto sensitivo-intelectual o intelectual-emotivo de lo bello (como aísthesis), ni solo el considerar todo el inmenso mundo cultural de las obras de arte, que es la cosa real transformada en cosa-sentido (el mero sonido como música; el mero color con pintura; etcétera).

La naturaleza es transformada en cultura. La Tierra, de pronto, se ha humanizado. Ya casi no queda naturaleza como naturaleza, sino que el ser humano la ha transformado (cambiando de forma: trans-forma-do) en cultura, en obra de arte, como un aspecto inescindible de toda obra de cultura. Y esto es la presencia del diseño que comienza a intervenir en todos los ámbitos de la producción humana (desde un libro, un tenedor, una ropa, un auto, etcétera): sería la estetización de todo instrumento material y simbólico cultural.

La filosofía griega hablaba de un lógos poietikós (la inteligencia que produce: la técnica en sentido helénico), razón o inteligencia productiva donde la belleza se emparentaba a la eficacia del medio, sin separarlas. Debemos ahora distinguir teóricamente el momento estético del meramente productivo; pero, acto seguido, debemos ahora reintegrar el momento estético en el mundo productivo como obra de arte o como todo útil, instrumento o mercancía estéticamente creado. Sería una estetización de la mera instrumentalidad cotidiana. La síntesis sería la aisthesis poiética, denominada como estética, donde ambos momentos son nuevamente articulados. Un embellecimiento global de los objetos y de la cultura como tal. La antigua descripción de la adecuada o 
recta razón-sintiente o el recto sentimientointeligente de lo a fabricar ${ }^{24}$ bellamente (kalós) queda ahora generalizado de nueva manera.

En la historia mundial, en todas las culturas cada campo estético desarrolló distintas reglas, ritmos, formas, estructuras, armonías, contrastes que no eran las mismas en todas las culturas. Hasta desarrolla un gusto (del que el individualismo metafísico de Kant sugirió que no podían ser generalizables o comunitarios) olvidando que sí existían esos gustos culturales analógicos. En el arte culinario le gusta a un chino el arroz preparado de una cierta manera, al quechua la papa (que puede prepararse en más de cuarenta maneras en el arte culinario quechua o aymara; es un gusto compartido que repugna a otros gustos culturales africanos, europeos o árabes). Surgirán así histórica y culturalmente las normas estéticas de la obra (ergonomía) que serán determinadas desde el horizonte histórico de las culturas, lo que nos abre ahora al problema más actual de la estética.

\section{HIPÓTESIS CUARTA. LA MUTUA DETERMINACIÓN DE LOS CAMPOS ESTÉTICOS $Y$ LOS CAMPOS PRÁCTICOS. LA DIMENSIÓN ÉTICO-POLÍTICA DE LA ESTÉTICA.}

Quizá lo más difícil de situar en la problemática actual de la estética es el cruce de los diversos campos $^{25}$. El romanticismo alemán intentó mostrar la prioridad de la estética sobre la ética, enseñando que por la estética el ser humano puede cumplir las exigencias de la

\section{El orthós lógos poietikós de los griegos.}

25 En este caso el campo de la estética es uno (sus subcampos como la pintura, la arquitectura, la música o la literatura, quedan englobados en el campo estético general). razón práctica, la felicidad, la perfección del bien y la justicia (relacionando así la Crítica de la razón práctica con la Crítica del juicio de Kant, pero dando prioridad a la segunda). Otros en cambio dan prioridad a la razón ética, política o económica (la estética como militancia revolucionaria) y sitúan la estética como un medio de realizar la justicia o un mejor orden futuro histórico-político. Se trata de una elección desde una última instancia: estética o práctica (y en los campos prácticos se prioriza la ética, la política, la economías, u otros campos prácticos).

Es fácil de mostrar ejemplos en los que el campo económico tiene prioridad sobre la estética. En el capitalismo la belleza diseñada de la mercancía que se expone en el mercado es ya un buen ejemplo. La mercancía diseñada por artistas (la moda del vestido, de los instrumentos, de la comida, del auto, etcétera) encandila al posible comprador (despierta una aísthesis deformada y generalizada por la propaganda de cierta mercancías) y parece embellecerse al sujeto mismo que usa un bello auto, un bello traje, una bella casa, etcétera. La mercancía alcanza mayor precio si es bella, y como tal muestra un valor de signo y diferencia, enseñaba Jean Baudrillard ${ }^{26}$, dentro de la lógica de la moda.

La moda es una intervención económicaestética en el mercado que da mayor valor de cambio a la mercancía en tanto es signo de diferencia para el que porta (como vestido) o usa (como auto) dicho instrumento. El que tiene un zapato, una ropa última moda es valorado como una persona superior, según la escala de valores del miembro de la sociedad capitalista.

26 Véase Crítica de la economía política del signo, Siglos XXI, México, 1974. 
Esa mercancía nueva destruye el valor de uso de las mercancías que dejan de estar de moda (el zapato puntudo impecable en su estado o valor de uso deja de estar de moda porque ahora los zapatos son chatos según la moda, $\mathrm{y}$ aunque todavía pudiera tener mucho tiempo para consumir su valor de uso ya no lo puede usar: el no estar de moda aniquila el valor de uso del zapato).

La moda, construida sobre la novedad estética de las mercancías como signo de superioridad (de la clase, de la raza, del más rico, etcétera), aumenta la venta de los productos, es decir, aumenta la tasa de ganancia (rate of profit diría K. Marx). La economía determinaría a la estética como un medio para su fin.

Un cierto análisis marxista standard igualmente da prioridad a la economía sobre la estética, analizando la producción de la obra de arte desde las condiciones económicas de sus productores (como sistema, como cultura, como individuos, como clase social). La teoría estética de los marxistas, tales como la de G. Lukács o Alfonso Sánchez Vázquez y la tan elaborada estética del marxismo occidental de la Escuela de Frankfurt, como el caso de Adorno en especial sobre la música, exigiría un trabajo que no intentaremos abordar aquí, donde estamos presentando hipótesis generadoras primeras de una estética de la liberación.

Pero de todas maneras, en todas ellas se estudia la relación del campo estético en el cruce con el campo económico solucionado en parte tal como lo proponemos a continuación, dando prioridad a un campo o instancia sobre el otro.

De lo que se trata en nuestro caso es de pensar un campo estético en donde no se pretende partir de una última instancia, sino pensar más bien en la mutua determinación de un campo sobre otro que en un proceso en espiral se encuentra por su parte determinada y es determinante de los otros campos siguiendo el desarrollo de dicha espiral ascendente histórico-cultural. Es decir, el campo estético puede (y es inevitable) estar determinado por el campo político, por ejemplo.

Así los frescos de los grandes pintores militantes mexicanos, como Diego Rivera o José Clemente Orozco, en que las obras de arte expresan una interpretación de la historia de un pueblo oprimido en proceso de liberación son expresión de una estética militante, comprometida y hasta revolucionaria. Lo mismo podría decirse de la pintura de Francisco de Goya, que de retratista funcional al sistema de la monarquía y la familia real borbónica se transforma en sus obras cumbres, donde expresa comprometidamente con los eventos políticos contra la invasión francesa del 2 de mayo de 1808, como por ejemplo en la pintura de Los fusilamientos, donde manifiesta el estado de rebelión del pueblo español ante esa ocupación napoleónica o en el cuadro de El Coloso ${ }^{27}$ donde dicho gigante es el pueblo español que se levanta sobre los Pirineos. Sus Pinturas negras expresan al pintor, obedencialmente ante los sufrimientos y la fealdad cotidiana de ese mismo pueblo, que podía surgir como un monstruo temible en la defensa de la patria, ya que vivía habitualmente en la oscuridad de la dominación.

Los dos Goyas, de la familia real y de los dolores del pueblo muestran ejemplarmente el compromiso estético determinado por exigencias normativas de la ética, la política y hasta de la economía (la pobreza expresada en el horror, aspecto contrastante a la belleza

27 Atribuido a algún cercano pintor del grupo de Goya. 
refinada de las infantas o de la Maja desnuda). La determinación del campo político sobre el campo estético de la obra de arte es evidente, mostrándose así que la obra de arte, en este caso la pintura de Rivera o de Goya, es una mediación para fines políticos, porque la integración en la obra de arte que toma como tema un acontecimiento político, en el que el pintor que está comprometido con sus pueblo y expresa bella o estéticamente ese contenido histórico político lo enmarca en el esplendor y la dignidad de la estética, transformando el grito de dolor en una obra de arte.

No es que el arte tenga una función política, sino que ciertamente presenta el acontecimiento revestido del aura de la belleza que el artista sabe crear. El arte produce en el espectador la experiencia de la aísthesis que emotivo-intelectualmente o sensiblecognitivamente refuerza con la belleza la relación afirmativa de la vida en ambos aspectos (como belleza de la obra y como acto heroico del pueblo). Se trataría del cruce donde la aísthesis y la obra estética potencian el significado de un evento político; es decir, el evento político goza de una valorización que el aura de lo bello agrega al acontecimiento. Lo contrario sería el triunfo de un artista que usa la política como un peldaño para el propio y solitario encumbramiento estético. Inevitablemente se entrelazan pero no son por su naturaleza última instancia del otro campo.

$\mathrm{Ni}$ el campo estético es mediación de lo político ni lo político esencialmente determina a lo estético. Sino que deben fecundarse mutuamente, en concreto y siempre; aunque frecuentemente uno domina o mediatiza al otro, como en el realismo soviético o el arte de la propaganda mercantil; lo instrumental mata a la estética y al campo práctico desnaturalizándolos. Como cuando los artistas (bajo las órdenes de Joseph Goebbels, responsable de la comunicación y publicidad del régimen nacional socialista y del arquitecto Albert Speer) preparaban minuciosamente como se diseña un edificio, las grandes manifestaciones del nazismo en Alemania, en las concentraciones por ejemplo de Nüremberg, con alarde de estructuras estéticas: iluminación con reflectores preferentemente de noche, multitudes disciplinadamente formadas y vestidas con uniformes bellamente, música que usaba las creaciones nacionalistas, como los Nibelungos de Richard Wagner con el sonido preferencial de la estridencia de las trompetas, todo lo cual crea el aurea de sacralidad que electrizaba a la multitud en la concentración política necesaria para exaltar la mística imagen del Conductor; aurea extraída claramente de la estética. Era un uso fetichista del arte.

$Y$ bien, pasando al tema en su esencia, debe decirse que el cruce del campo estético con el ético-político permitirá a la estética subsumir las categorías de esos dos campos prácticos y la estética se aproximará así a su producción histórico-concreta.

De ninguna manera negamos la necesidad de la articulación de la estética con los campos prácticos. Al contrario, exigimos su mutua determinación, sin perder cada campo su autonomía respectiva. Ningún artista mediocre por articularse a una política progresista o de izquierda es mejor artista. Ningún mal político por embellecer su propaganda es mejor político. Valdría el dicho Zapatero a tus zapatos. Si son bellos los zapatos serán útiles para el político. Si las acciones políticas son justas serán más apreciadas con buenos zapatos. 
Ante las acciones complejas practicas la estética debe saber descubrir el hecho de que le es inevitable la articulación con dicho campo (ético, político, económico, etcétera) y que queda mutuamente determinado por aquellos. La cuestión para el artista es tener clara conciencia de su compromiso con quién, por qué, en qué, etcétera, situación práctica asume como su contraparte en su articulación. Debe saber jugar, arriesgar, comprometer su dominio estético en una causa adecuada, justa, honesta, ética.

Dos textos guiarán nuestra reflexión en las restantes tres hipótesis. Cita Israel Martínez Ruiz ${ }^{28}$ una reflexión de la Junta del Buen Gobierno de la Realidad (comunidad zapatista en Chiapas, México):

Una cosa queremos compartir, es sobre los murales que para nosotros son muy importantes. Porque es otra forma de expresar o contar nuestra historia. Aunque al principio tuvimos problemas, porque los hermanos $y$ hermanas pintores llegaban a pintar lo que ellos querían o pensaban, pero nos dimos cuenta que al final no le entendiamos porque solo ellos sabian lo que iban a mostrar [...]. Después se les pidió que juntos se haga lo que queremos expresar. Entonces empezaron a formar equipos de muralistas. Ahora nosotros, o sea el pueblo, es el que dice qué es lo que quiere que se pinte, para que acualquiera quellegue a visitarnos podamos explicarles lo que significa. ${ }^{29}$

28 En su obra La praxis del arte contemporáneo en Chiapas, Tesis de Maestría de la Universidad de Ciencias y Artes de Chiapa (México), marzo de 2017.

29 Op. cit., pág. 113. Hemos modificado algo el texto.
Expresado lo mismo por Alessadro Zagato en el relato de Natalia Arcos de la siguiente manera Supe que llegaron ciertos artistas extranjeros a pintar en un Municipio Autónomo [zapatista] y que no pudieron hacer su proyecto original, porque la comunidad les pidió otro lenguaje pictórico que fuera comprendido por todos ellos. ${ }^{30}$

Este contar con el acuerdo y con la colaboración de la comunidad expresada pictóricamente es lo que René Mancilla, arquitecto tantas veces premiado por su obras entre las comunidades originarias del desierto de Atacama en Chile, llama los Códices arquitectónicos dibujados por la comunidad que vivirá en la obra que se construye comunitariamente: es decir es a partir de esos Códices producidos consensualmente a partir de los cuales el equipo de arquitectos diseña definitivamente casas, escuelas, edificios públicos, plaza recreativas y con los materiales tradicionales (mejorados) y desde el tipo de belleza tradicional pero novedosa, creativa, creciente.

Los especialistas participan de las discusiones con la comunidad que se concretan en códices dibujados y explicados por todos sus miembros. Los especialistas estudian esos códices y después proponen proyectos arquitectónicos. La comunidad los discute y corrige. Los arquitectos modifican sus propuestas. Y como en un ininterrumpido ir, participar y volver a proponer, se alcanza al final la decisión de lo que se ha de producir. El consenso de la comunidad es el origen de la obra estética diseñada. El arquitecto cumple con lo que podemos denominar una estética obediencial: obedece el gusto y la necesidad de la obra de la comunidad.

30 Notas sobre estética y política en el movimiento zapatista, en revista Rufián, enero (2014), p. 17. 
Como cuando en la Política de la Liberación descubrimientos en torno al 2006 que la concepción de la política desde la noción de poder obediencial ${ }^{31}$ (enunciada por el FZLN en Chiapas y por Evo Morales en Bolivia), de la misma manera ahora se capta el principio fundamental (normativo, ontológico y metafísico, esto último en el sentido levinasiano) de una Estética de la Liberación. Lo que llamaremos estética obediencial (analógica al poder obediencial de la política) enuncia la hipótesis originaria de estas tesis. De paso supera con creces la estética kantiana de los genios artistas y del mismo H. Marcuse que en Eros y civilización sitúa la novedad estética en la imaginación de los artistas (individuales), ambas visiones semejantes a la de Kant, y en gran parte de la Escuela de Frankfurt.

Todas ellas están limitadas por el individualismo moderno y por la incomprensión de la historia mundial de la estética. Por ejemplo, las grandes obras arquitectónicas de la humanidad, ¿los jardines colgantes de Babilonia, las pirámides egipcias, el Partenón ateniense, la tumba romana de Adriano base de las basílicas bizantinas y éstas últimas punto de partida del arte musulmán de las mezquitas, los templos hindúes de Madurai o los ya islámicos de Agra (como el Tajh Mahal), la arquitectura china, las iglesias góticas de la cristiandad latina (en el esplendor de la catedral de Köln), las inmensas pirámides aztecas (con más de 11 mil conjuntos piramidales en solo México) o las mayas, la precisión de las murallas de Sacsayhuaman de Cuzco, etcétera, fueron obras de genios kantianos o de pueblos durante milenios? ¿No eran acaso, como exige

31 Mi 20 tesis de política (Siglo XXI, México, 2006, en inglés en Duke University Press), tesis 4. la autorizada comentadora zapatista, obras de arte comprensibles para el pueblo porque creadas por ellos? Los grandes artistas genios de esas culturas ¿no fueron acaso observadores y productores obedenciales que supieron expresar la estética del pueblo, de las comunidades, de las pequeñas y grandes culturas que son fruto comunitario de expresión de un tipo de belleza que surge del consenso de sus miembros durante centenas y hasta miles de años?

La ética le permite a la estética subsumir principios normativos (como exigencias éticas universales válidas para las culturas particulares) ${ }^{32}$ que fortalecen los principios propios de la estética. Según el principio material o de la obligación en todo acto de la afirmación de la vida humana, la estética gana en claridad y voluntad ya que partiendo del descubrimiento de la belleza como la disponibilidad de las cosas reales y las obras de cultura como mediaciones adecuadas para la vida, según la aísthesis, ahora se exige deónticamente practicar la acción estética para afianzar la voluntad-de-vida (Lebenswille) de un pueblo, de todos los pueblos, que es el contenido último de la misma estética.

El principio del consenso práctico (en la ética) o de legitimidad (en la política) fortalece la concepción comunitaria de la estética, no como contemplación emotiva individualista sino como experiencia comunitaria. De la misma manera el principio de factibilidad le dará mayor realismo en el uso de los medios para la producción colectiva de la obra de arte.

Pero según veremos, serán los principios críticos ético-políticos los que definirán la diferencia entre una estética del sistema vigente

32 Considérense los seis principios normativos en mi Ética de la Liberación (Trotta, Madrid, 1998, en inglés en Duke University Press, Durham, 2013) 
como dominación, de la estética de los dominados o excluidos como una estética crítica, como una Estética de la Liberación (en la hipótesis seis más adelante). Por lo general, las estéticas vigentes son las de los grupos (los cultos), las clases (la burguesía en la modernidad), las culturas dominantes (el eurocentrismo estético, por ejemplo), cuestiones que pueden tratarse contando con categorías prácticas como la de totalidad, alienación, exclusión, liberación, etcétera. Ciertamente son estéticas, pero defectivas, necro-estéticas. ${ }^{33}$

De igual manera, teniendo en cuenta la política, si el poder residía en la comunidad política, en el pueblo (como expresaba el texto del zapatismo) de igual manera es en el pueblo donde reside ahora la potentia aesthetica creativa última en sí todavía, que como analógicamente en la política exige su expresión objetiva (en la política como instituciones [potestas] y en la estética como obras de arte). Y así como la representación política se puede fetichizar corrompiéndose, así el artista individual (aun el genio) puede creerse el origen de la creación de la obra de arte, olvidando la comunidad.

¿Qué es el Jazz, que tanto odiaba Adorno, sino una expresión (al igual que el tango) que nace en la música del África en torno al tambor cuyo ritmo, tonalidad y armonía llevaron los esclavos del África a Estados Unidos, convirtiéndose en la música que marca el paso a la danza de la juventud en todo el mundo? ¿Quién diría que la música y la danza más presente en el mundo fuera la africana $y$ no la romántica alemana de un Beethoven, que de todas maneras se inspiraba también en la música popular alemana?

33 Usando la expresión de Achille Mbembe de la política (necropolítica) analógicamente en la estética.
De igual manera por ejemplo, el campo económico y técnico puede determinar y ser determinado por el campo estético. Así en la arquitectura el campo económico puede determinar nuevamente a la comunidad que puede sugerir los materiales constructivos, las reglas culturales en vigencia de los grupos populares, que bajan los costos y usan la producción del lugar, ateniéndose a ciertos principios técnicos que aunque sean mejorados inspirados en otras experiencias, guarden coherencia cultural con el entorno. Y de nuevo, habrá que aplicar principios críticos estéticos para que las comunidades oprimidas o excluidas puedan recibir el beneficio de la belleza en sus espacios arquitectónicos de todo tipo, usando formas, estilos, materiales propios. La especial atención a esos grupos más pobres es el fruto de la intervención de una Economía de la Liberación. ${ }^{34}$

Por supuesto que también el campo teórico o las concepciones ideológicas de la estética determinan a las prácticas estéticas. La estética romántica alemana, que se levantó contra el racionalismo ilustrado del siglo XVIII, con su teoría de Strum und Drang (tempestad e impetu) con figuras como W. Windelband, F. Schiller, F. Schlegel, Novalis o F. Heine, conmovieron las teorías y las prácticas del arte, pero al mismo tiempo teóricamente inventaron el helenocentrismo estético como origen clásico del Renacimiento y del eurocentrismo estético e histórico que culmina con Hegel. Es

34 Véase mi obra 16 tesis de economía política, Siglo XXI, México, 2015, donde también estudio la intervención de los principios normativos en la economía, que pueden por su parte ser subsumidos en la estética. La economía determina ciertamente a la estética. El esplendor de las pirámides de Egipto fueron posibles gracias al inmenso trabajo de esclavos y por los altos tributos de los campesinos del Nilo. 
el despertar de la exclusión de lo germánico por el pensamiento enciclopédico francés que movió el péndulo hacia el otro extremo, con el romanticismo, situando a la cultura del Norte de Europa con pretensión de ser la culminación de la historia mundial de la estética. Veremos algunos aspectos de esta temática en las dos hipótesis siguientes.

\section{HIPÓTESIS QUINTA. EL ESTETICIDIO QUE PRODUCE EL TIPO DE BELLEZA CLÁSICA GRECO- MODERNA EUROCÉNTRICA DE LAS ESTÉTICAS COLONIALES.}

El fetichismo de la totalidad estética desde Grecia a Europa crea lo que podemos denominar la estética eurocéntrica, centralidad labrada lentamente desde 1492 es decir, en la modernidad. Esa pretensión de centralidad producirá inevitablemente la negación del valor de todas las otras estéticas; será un auténtico esteticidio, como un aspecto central de la instalación de la bipolaridad que comienza a formarse en el Caribe de la modernidad/ colonialidad. Los otros mundos culturales fuera de Europa serán juzgado como primitivos, bárbaros, sin belleza alguna, en el mejor de los casos, folklóricos.

Seráuno delos momentos en quela matriz de la colonialidad del poder, la subjetividad, la cultura cobrará mayor impulso. La víctima dominada será juzgada como lo brutal, salvaje, con una fealdad estética inocultable. La estética de lo feo (de la fealdad: kakós en griego) se aplica fuera de las fronteras de Europa. Estos juicios estarán sostenidos por escalas clasificatorias de los tipos de humanidad, que hasta por su forma y las dimensiones craneanas, el color de la piel, la extrañeza de sus hábitos, comidas, vestidos, música, danza, arquitectura, etcétera evidencian tipos humanos inferiores. Sin lugar a duda la piel negra del africano y de otros colores en diversas culturas, darán pie a un racismo que será un medio privilegiado para marcar hasta en la naturaleza de la corporalidad la superioridad de la estética occidental.

Como lo expone Jack Goody ${ }^{35}$ la modernidad se ocupó primeramente en estudiar y aprender los archivos de las otras culturas. El propio Durero quedó admirado al contemplar la precisión y miniatura de las joyas de los aztecas que los españoles conquistadores hicieron llegar a sus manos. Como otro ejemplo piénsese en la estética del Renacimiento y su vinculación nunca claramente explicitada con el Bizancio griego-cristiano tomada militarmente por los turcos en $1453^{36}$ y qué decir de los chinos, admirados en el siglo XVIII y vituperado posteriormente.

Esos archivos después de haber sido estudiados y asimilados se los tomó como punto de partida de un innegable crecimiento propio. Pero una vez asumidos y desarrollados los ignoró como sus fuentes, y los denigró como primitivos, atrasados, salvajes, en el caso ejemplar del llamado despotismo oriental en el siglo XIX, habiendo la China contribuido con elementos fundamentales de la cultura moderna, iniciando la Revolución industrial antes que Inglate$\mathrm{rra}^{37}$ e igualmente haciéndose presente en la

35 The theft of History, Cambridge University Press, New York, 2007.

36 Esto significó la emigración de la élite bizantina, griega, a Italia, que se dejará ver de inmediato en la pintura, la arquitectura y en otros campos de la estética.

37 Véase la obra de K. Pomeranz, The great divergence: China, Europe and the Making of the Modern World Economy, Princeton University Press, 2000. 
estética con las llamadas chinoiseries en el vestido, la pintura, la decoración de muebles, todo tipo de instru-mentos, etcétera.

Una vez creada la retórica del milagro estético griego en la Antigüedad como origen de la tradición que culmina en la modernidad como milagro europeo, se dan las bases teóricoideológicas del eurocentrismo estético que juzga a todas las otras estéticas, tal como lo hemos dicho, como infantiles, primitivas, bárbaras, kitsch. Es un momento central de la modernidad/colonialidad, no reconociendo Europa todo lo que debió a las culturas dominadas coloniales del Sur que desaparecen en una amnesia total del origen de casi todos los descubrimientos modernos.

Se trata de un esteticidio -lo llamaría Boaventura de Sousa Santos- porque no solo hay desconocimiento de la creación estética de las grandes culturas del Sur, sino que todo comienza a priori con la pregunta: ¿Qué pudieron producir de belleza, de estética esas culturas bárbaras? Y la respuesta es negativa o al menos no se descubre en ellas ningún elemento que pudiera servir como momento de creatividad, de novedad estético mundial, por su atraso o barbarie.

Para esa descalificación de las grandes culturas transformadas en la modernidad como mundo colonial también estético, nada mejor que la invención de una historia mundial del arte formulada clásicamente en el esquema de la historia universal hegeliana, hecha clásica, desde la inventada Antigüedad (todas las culturas fueron preparatorias teniendo como culminación Grecia y Roma en un movimiento del oriente al occidente), la llamada Edad Media (como período consecutivo mundial, siendo solo el hecho del aislamiento de
Europa detrás del muro que construyó el arte islámico y al final el Imperio Otomano, estética islámica que se cultivaba desde el occidente del Atlántico con Marruecos hasta el oriente del Pacífico en la isla de Mindanao en Filipinas) y por último, la Modernidad (que se inicia con el 1492 que origina simultáneamente el capitalismo, la colonialidad, el racismo aplicado mundialmente, el eurocentrismo como ontología e ideología dominante, y el esteticidio del mundo colonial o del Sur global).

Sobre ese esquema se escriben todas las historias del arte mundial y nacional, no solo de los países del Norte sino igualmente las historias de todas las culturas reducidas a haber logrado obras atrasadas y rudimentarias claramente diferenciadas como experiencias estéticas coloniales. Las primeras del Norte como creadoras, innovadoras, bellas por excelencia, modernas, y las coloniales del Sur se valoran en la medida que miméticamente imitan defectuosamente a las primeras. En el mundo colonial la estética queda definitivamente escindida en (a) el arte practicado por la elite dominante colonial, que es mimético y juzga eurocéntricamente la belleza en la colonia y por ello desprecia lo propio y lo popular y (b) el arte popular, tradicional, que aunque frecuentemente se reconocen sus impresionantes obras del pasado como meros antecedentes sin continuidad, como puede observarse en las culturas chinas, indostánica, islámica (desde la antigua Mesopotamia), igualmente africanas (desde el antiguo Egipto y su extensión a la sabana y al horizonte bantú), mesoamericana o inca que goza de vitalidad hasta el presente, pero serán catalogada como tradicionales, rudimentarias, bárbaras, naiv o folklóricas.

Todo esto produce inevitablemente el juicio de un vacío absoluto de la estética co- 
lonial, que como Walter Mignolo lo señala, ${ }^{38}$ por no ser modernos caen fuera del espacio y del tiempo creativo de la estética. Toda obra estética no-moderna desde el Tawantinsuyu andino hasta la China de los Ming es objeto de un juicio esteticida, una necro-estética que deja en la exterioridad del no-ser, en la exclusión de considerar como obras estéticas de los pueblos de todas las culturas coloniales. En México se consideraban los grandes monumentos, las pirámides aztecas, como amontonamiento de piedra con las que se edificaban las catedrales, los monumentos coloniales y hasta las casas de los patricios.

Hubo de llegar un artista alemán en el comienzo del siglo XX y considerar esas piedras como espléndidos ejemplos de arte para de pronto, cambiar la interpretación de esos objetos (que por otra parte habían sido frecuentemente considerados como demoníacos en el siglo XVI) para ahora sí se los mostrara como obras estéticas y culturales en el Museo de Antropología de la capital. ¿Por qué como obras demoníacas?

En efecto, esto debido al juicio de ¿quiénes pudieron construir tamaños monumentos? No pudieron ser los indígenas dominados, porque habiendo perdido por la conquista su organización política, económica, cultural, sus élites de sabios y artistas (los tlamatinime aztecas o amautas entre los inkas) altamente ilustrados y sus antiguas costumbres eran despreciados por los conquistadores. Habían sido reducidos a una violenta barbarie $\mathrm{y}$ aquellos ingentes materiales fruto de sus

38 Walter Mignolo lo señala en el Epílogo, de Habitar la frontera. Sentir y pensar la descolonización (Antología 19992014), Universidad Autónoma de Ciudad Juárez, C. Juárez (México), 2015, p. 468. manos no podían ser fruto de esos pueblos primitivos. Eran por ello los demonios los que habían debido fabricar esas obras espléndidas de cultura, de arte.

Ya en 1973 en una exposición presentada en las Semanas Latinoamericanas de la Universidad de El Salvador en Buenos Aires, tratamos el tema de Cultura imperial, cultura ilustrada y cultura popular ${ }^{39}$ donde analizamos como el esteticidio de la cultura popular no es solo debido al eurocentrismo modernidad/ colonialidad sino igualmente a la colonialidad interna asumida como dominadores en América Latina por la elite criolla blanca (como los clanes brahmánicos en la India, y de otra manera y nombres en todas las culturas del Sud). Hay como una correa de transmisión de la negación de la cultura popular de parte del eurocentrismo en el centro y en la periferia. Para no extendernos en esta hipótesis quinta recomendamos leer los artículos citado en mi obra Filosofía de la cultura y Transmodernidad, donde se encuentran materiales que reflexionan sobre esta cuestión. ${ }^{40}$

39 Considérese la reciente recopilación de mis ensayos sobre cultura y estética, publicados en Filosofía de la cultura y Transmodernidad, UACM, México, 2015, pp.189-229. Este último trabajo es seguido de otro bajo el título Arte cristiano del oprimido en América Latina (Hipótesis para caracterizar una estética de la liberación) (pp. 231-256). También se toca el tema el capítulo Cultura latinoamericana y filosofía de la liberación (Cultura popular revolucionaria, más allá del populismo y del dogmatismo), en pp.257-330. Era el tiempo de la producción estética bajo la conducción del gran poeta latinoamericano y cósmico universal Ernesto Cardenal que fungía como ministro de cultura en Nicaragua y que impulsó la creatividad popular como nunca se había hecho. Todo lo que se dice de la cultura vale para la estética.

40 Los textos están en www.eniquedussel.com/obras. 


\section{HIPÓTESIS SEXTA. DE LA DESCOLONIZACIÓN DE LA ESTÉTICA A LA ESTÉTICA DE LA LIBERACIÓN}

Descolonizar encubre una negatividad (negar la colonialidad estética); liberar en cambio indica el momento positivo, crear la nueva obra de arte, la nueva estética. Por lo tanto nos enfrentamos al momento poiético o creador del nuevo momento estético.

La crítica del fetichismo de la belleza del sistema estético eurocéntrico, occidental, moderno debe ser asumido (en lo mejor que se pueda recuperar, como en las trompetas del Jazz que es un instrumento moderno o un museo de arte islámico) pero subsumido dentro de otro horizonte el del nuevo sujeto o actor colectivo de creación estética que son las culturas y los pueblos colonizados en el camino de su liberación.

El ejemplo de la construcción de museos de obras clásicas de las culturas coloniales indica el nacimiento de la autoconciencia del proceso autónomo que exponen las obras de arte de las escuelas estéticas en los diversos campos (la pintura, la arquitectura, la música, la danza, la literatura, y por ejemplo del cine como medio masivo estético, considerando que Mombay en la India es la productora de este arte que supera a Hoollywood en número de películas y de espectadores de ellas, etcétera) manifiesta ya positivamente la descolonización de las que estamos hablando.

Veamos una dimensión que W. Mignolo denomina Activar los archivos, decentralizar a las musas ${ }^{41}$ La descolonización en uno de sus aspectos, se sirve igualmente de la fuerza de los Estados que descubren no solo su autonomía

41 En la Antología citada, pp. 415 ss. (aunque a veces precaria) sino igualmente la cultura estética propia. En la cultura árabe el arte ha sido central. El llamado arabesco, que aparece como siendo un monolito de mármol (y que es en realidad el producto de una masa muy dúctil y de fácil manejo para el artista, cuando al comienzo no es sino polvo de mármol que con otros componentes se transforma en un masa arcillosa que seca adquiere gran dureza) ha producido obras de arte arquitectónico de magnificencia inigualable.

El Museo de Arte de Doha o el Museo de las Civilizaciones Asiáticas de Singapur han de entenderse que en la estética los museos significan la autodefinición del arte de una cultura y un Estado. Hay museos en Francia como Le Louvre, en Inglaterra como el Museo Británico, el Museo de Berlín en Alemania, todos como manifestación estético-política. Los museos nombrados en primer lugar, que se originan en naciones que han sufrido el colonialismo cultural-estético son ya un signo de un proceso positivo de auto-manifestación de la dignidad de su creación estética. El ya antiguo (y no tan ordenado) Museo de El Cairo como el de Antropología en México son ejemplos de lo dicho. Los nuevos museos en los países más ricos del mundo árabe-musulmán y la actual organización de cientos de museos regionales en la China por ejemplo, nos muestran este estado de cosas.

No siempre son ejemplo de inspiración que se oponen a la occidentalización o al eurocentrismo, pero manifiestan ya un proceso de liberación evidente. Esto es fruto de algo mucho más profundo e importante. Es la producción artística propia de los pueblos que comienzan a descubrir sus propia aísthesis (o comprensión de la belleza) y que lentamente, 
con instrumentos propios o modernos (frecuentemente modificados) exponen sus obras de arte, como por ejemplo en la música. Pero igualmente en la pintura, la literatura, la danza, la arquitectura, etcétera.

El núcleo creador de la nueva estética está cifrado en las comunidades culturales que han guardado su originalidad primera, y que denominamos hace decenios como las comunidades que poseen una cultura que en ciertos momentos históricos se tornan en culturas popular-revolucionarias, como el Sandinismo nicaragüense bajo la inspiración de Ernesto Cardenal, el poeta cósmicopolítico, o del zapatismo mexicano con clara conciencia de su creatividad estética gracias al Subcomandante Marcos en literatura.

En esos casos la comunidad educa al artista y crea lo que hemos llamado una estética obediencial. Es necesario ponerse a la escucha ${ }^{42}$ (no solo en la música, sino en todos los campos de la estética) y solucionar de nueva cuenta la aporía kantiana entre la estética popular y el genio artístico. Repasemos por un instante algunas de las tesis de Kant.

Nuestro filósofo expresa en La crítica del juicio que la obra de arte es un modo de representación que estimula la cultura (Kultur) de las fuerzas espirituales para la comunicación socia $^{43}$ que exige en el espectador el juicio de gusto pero que tiene por causa creativa la imaginación como facultad productiva (Einbildungskraft) ${ }^{44} \mathrm{del}$ genio. Por ello para juzgar los objetos bellos como

42 Obediencia tiene una etimología latina, significa oír (audire) lo que se tiene delante (ob-): ob-audire (obedecer).

43 Kritik der ästhetischen Urteilskraft (parte de la Crítica del Juicio), § 44, B 179, A 177 (Kant, Werke, Wissenschaftliche Buchgesellschaft, Darmstadt, 1968, vol. 8, p. 404).

44 Ibid., § 48, B 188, A 185, p.410. tales se necesita el gusto y para el arte belleza; y para producirlos (Hervorbringung): genio. ${ }^{45}$ Para Kant la acción creativa estética es entonces propiamente la realizada por el genio: el genio es el talento, el don natural, que da la regla al arte. ${ }^{46}$

Una Estética de la Liberación en cambio, debe recordar el testimonio de la comunidad maya zapatista. En primer lugar, nos hablan de ciertos artistas extranjeros ${ }^{47}$ que llegan a la comunidad maya (para ellos exótica por la arquitectura, el color de sus vestidos y de su piel, por la naturaleza tropical bellísima y abundante) para realizar la tarea del artista: producir una obra de arte acorde con este contexto. El artista es este caso se comporta como un singular como el genio kantiano. No advierte que su individualismo moderno (igual al de Kant) está determinando su creatividad.

Claro que preguntará a la comunidad sobre su historia, costumbres, etcétera, para plasmar todo ello en su obra de arte que ofrecerá a la comunidad como objeto de lujo cultural. Pero la comunidad de inmediato pone en cuestión al artista, como al pretendido genio, al origen mismo de su creatividad: Los hermanos $y$ hermanas pintores [de afuera] llegaban a pintar lo que ellos querían o pensaba, pero nos dimos cuenta que al final no los entendiamos porque solo ellos sabian lo que iban a mostrar. ${ }^{48}$

El genio tenía su proyecto para la comunidad; pero la comunidad, con plena autoconciencia de ser el sujeto colectivo de la creación artística, debió disciplinar a los extranjeros e integrarlos a la comunidad:

45 Ibid., § 49, B 194, A191, p. 414.

46 Ibid., § 46, B 181, A 178, p. 405.

47 En texto copiado supra.

48 Texto citado supra. 
Después seles pidióquejuntos se haga

lo que [nosotros] queremos expresar.

Entonces se empezaron a formar equipos de muralistas. ${ }^{49}$

Es decir cada equipo de muralistas (sin experiencia pictórica pero con mucha memoria de sus tradiciones) comenzaba a hacer su propio camino estético-comunitario. Es de notar la claridad epistemológica de esos artistas populares. El pintor especialista que vino de afuera ahora era integrado pero para ayudar a los miembros de la comunidad a comenzar a pintar con sus propias reglas, pautas (es como el cantor que comienza a cantar con su propia voz, su ritmo, sus reglas; o el constructor que fabrica su casa desde el modo de ponerlas en pie según su tradición, o la que confecciona su vestido con los bordados ya conocidos desde el tiempo de sus abuelas, etcétera). Es la comunidad, el pueblo el que ya conoce el contenido de la obra de arte y desea aprender ${ }^{50}$ a crearla.

El pintor extranjero (¿por qué no pintas angelitos negros?, dice la canción popular ${ }^{51}$ ) se ha transformado en el sujeto de una estética obediencial siendo la comunidad la sede creativa de toda obra estética como lo fue siempre desde hace siglos y milenios en todas las culturas de la humanidad. El ser la sede originaria de la capacidad creadora es lo que denominaremos, analó-

\section{Ibid.}

50 Aquí se articulan el campo estético y el campo práctico pedagógico. La pedagogía comunitaria determina ahora la estética popular y viceversa.

$\mathbf{5 1}$ Es la propuesta de una comunidad afro-latinomericana (expresada por un poeta militante) que sabe que el demonio es negro por ello le piden al artista blanco que pinte angelitos, santos, y aun un Dios negros. Es la interpelación del pueblo al artista alienado eurocénrico. gicamente a la política, la potentia aesthetica. ${ }^{52}$ La comunidad estética no es la que obedece las reglas de los genios (kantianos) ${ }^{53}$ sino que son los miembros de la comunidad como el sujeto de la potentia que crea dando el contexto histórico estético (los que obedecen son ahora los genios transformados en artistas obedienciales). Es el pueblo el que crea en última instancia. ¡Aun L. von Beethoven fue un oyente, un obediente al canto de los campesinos que festejaban la vendimia junto al Rhin! Su inspiración, el asombro de la aísthesis del creador no le vino por estar en la Opera, sino por la experiencia emotiva, creadora del pueblo simple alemán al que supo escuchar cantando y danzando con su oído estético educado y genial. Como enuncia la sabiduría semita: ¡Que cada mañana me despierte con el oído atento del discípulo!

El pueblo es el sujeto colectivo del gusto y por esto los gustos en principio son comunitarios. Así es como un árabe gusta una tortilla de trigo de una cierta forma y una cierta manera de su cocción y un azteca le gusta una tortilla de maíz de otra forma y consistencia. Los gustos son culturales, comunitarios, aunque pueden haber diferencias individuales dentro de la comunidad (solo en ciertos aspectos y como excepción y en esto Kant tiene razón). Pero no es cierto que sobre gustos no haya nada escrito.

Dicho juicio es propio del individualismo moderno, solipsista ya que siempre responde a una base común solidaria. Es por ello que una cultura eurocéntrica en los gustos culinarios

\section{Véase 20 tesis de política, tesis 2.}

53 En realidad, el genio auténtico es el que mejor interpreta el geniopopular. Beethoven (y tampoco Einstein con respecto a la teoría de la relatividad) no hubiera podido crear el Canto de la Alegría si hubiera nacido entre esquimales, por ejemplo. Es tan obvio que pareciera ridículo simplemente enunciarlo. 
considera a la de los otros pueblos coloniales como primitivos, no comible y les causan nauseas; es decir, no son los propios.

Ciertamente la estética tiene reglas comunitarias, históricas, pero flexibles dentro de ciertos límites. Y a causa de lo indicado concluyen los mayas de Chiapas que: Ahora nosotros, o sea el pueblo es el que dice qué es lo que quiere que se pinte. ${ }^{54} \mathrm{Y}$ lo toman como propio, lo comprenden, lo pueden transmitir a las nuevas generaciones y a los extranjeros que los visitan. No es un mero querer autoritario, sino un querer comunitario que produce la obra de arte y de la cual se tiene pleno dominio que se expresa en esta confesión: para que a cualquiera que llegue a visitarnos podamos explicarles lo que significa. ${ }^{55}$

En la llamada Edad Media europea en las catedrales góticas el pueblo rememoraba en los retablos, con sus bajorrelieves de frisos y los vitrales de las ventanas las historias que todos conocían en las que el pueblo era educado en sus propias tradiciones. Era la obra de arte que reafirmaba a la comunidad en su identidad. Lo mismo acontecía en todos los grandes monumentos artísticos de la humanidad. La modernidad arrebató a los pueblos coloniales la capacidad de su autoexpresión, y en la colonialidad estética se ocultó lo propio de cada una ellas y se exaltó una estética pretendidamente mundial, occidental y eurocéntrica.

Los zapatistas indican un camino a la Estética de la Liberación que solo hemos bosquejado resaltando algunos aspectos, de los tantos que habrá que desarrollar para

54 Ibid.

55 Ibid. superar el eurocentrismo en boga de las así llamadas historias mundiales de la estética. La fetichización de una cultura y su estética (la europea norteamericana) ha producido así la muerte de otras estéticas, que renacen sin embargo de entre las cenizas que se han mantenidos vivas debajo del fuego colonizador.

Habiendo ya expuesto lo aquí escrito deseo efectuar una última reflexión. Alguien podrá objetar: ¿Pero no puede soslayarse que haya miembros de una comunidad, que viviendo profundamente los gustos, las reglas, la experiencia de la propia estética comunitaria, tienen donen naturales, un oído y memoria acústica muy por sobre la media, habiéndose dedicado apasionadamente de manera disciplinada en la técnica necesaria de manera no común lo que le da un dominio en la ejecución de las obras de su campo, como por ejemplo en el arte musical; o una percepción instantánea y profunda muy desarrollada para el color, el sentido de la perspectiva, la profundidad de los espacios, el uso de la luz y la sombra, y tantos aspectos necesarios para la pintura, y, además, habiendo tenido maestros de gran conocimiento y práctica en su campo estético, lo que le permite expresar la belleza (arraigada en la de su pueblo), lo que nos hace comprender la intención innegable de Kant en lo que élllamaba el genio, pero situado en su caso sin referencia constitutiva a la comunidad como origen de su inspiración (inspiración que no es sino el avivamiento coyuntural de la aísthesis).

Lo esencial es saber dónde se encuentra el fundamento (en el individuo solipsista o en la comunidad en la que vive y es educado el artista obediencial). Hay entonces dos posturas: o la del genio que singularmente determina la creación de la obra de arte que se populariza en 
la comunidad posteriormente; o la del artista obediencial que tiene el genio de interpretar el latido oculto de la belleza viviente de una comunidad histórica en su estado latente pero presente, que sabe oír atentamente esos latidos para otros inaudibles a fin de desarrollar en plenitud una obra que expresa al mismo tiempo la estética comunitaria pero también la realización novedosa, original, de mayor perfección de lo conocido hasta ese presente histórico por un pueblo.

El que al sentir e interpretar esta corepresentando el sentir común ${ }^{56}$ de una manera profunda, que parte y admira la aísthesis de la comunidad, no puede sino recibir por parte de la comunidad, el aprecio, el aplauso del artista singular por su osadía y perfección, siendo consagrado por el mismo pueblo como el mejor y más coherente miembro en la comprensión y sensibilidad de la estética de la comunidad.

De esta manera nace el genio artístico singular, expresión obediencial ante un pueblo, por llevar a la aísthesis y a la obra de arte comunitaria a su pleno desarrollo. Un Chopin en su Polonesa heroica (un ejemplo eurocéntrico), expresa al pueblo polaco en una coyuntura política crítica dónde el genio celebra la percepción estética de la comunidad y la obra de arte nutre a la comunidad para vitalizar (como hiperpotentia aesthetica) el patriotismo en estado de rebelión, de aspiración hacia la liberación. El genio nace desde el presupuesto de la estética comunitaria y es su consagración; siendo siempre la sede ontológica y el actor protagónico el pueblo mismo como potentia aesthetica.

56 El creador de una obra de arte inevitablemente la hace ante un espectador virtual que, en último término, es su propio pueblo donde ha nacido y para el cual expresa en esa obra el sentir del mismo pueblo.
Valga casi al final de estas hipótesis volver sobre el paradigma de la liberación, que muy resumidamente podría exponerse así. En un primer momento, dado un sistema mundial iniciado en 1492 donde la oposición modernidad/ colonialidad es constitutiva de ambos términos de la relación, la modernidad ha pasado por ser el sistema vigente estético hegemónico que como el ser parmenídico se afirma ante el no-ser, la exterioridad, el Otro. En un segundo momento, dicho no-ser, que el mundo estético colonial, del Sur negado después de cinco siglos, toma conciencia de sí mismo, entra en un estado de rebelión y se anuncia al comienzo como pura negatividad. Niega la estética moderna y comienza un movimiento descolonizar, que se cumple en todos los niveles, desde la epistemología estética, a las prácticas, a la protesta, etcétera.

Sin embargo, y el más necesario es el tercer momento, que no es puramente negativo sino positivo, creador, emergiendo una nueva experiencia de la aísthesis que se expresa en una revolución al nivel de las obras de artes en todos los campos, superando así el fetichismo de la belleza moderna e inaugurando la irrupción de diversas estéticas que comienzan a dialogar en un pluriverso transmoderno donde cada cultura estética dialoga y aprende de las otras, incluyendo la misma modernidad (destituida de su universalidad y situada como una particularidad muy desarrollada ciertamente)

La Estética de la Liberación piensa esta temática y sabe que el camino hacia una estética futura pluriversal (no universal por la imposición de la estética de una sola cultura dominante) significará una sin-fonía (muchas expresiones musicales en diálogo y mutuo aprendizaje) respetuosa de las distinciones analógicas que se darán entre todas ellas. Y así 
proponemos, como proclaman los zapatistas en otros horizontes: ¡Otra estética es posible!

\section{HIPÓTESIS SÉPTIMA. NUDOS QUE SE CONSTITUYEN ENTRE LAS MUTUAS DETERMINACIONES DEL CAMPO ESTÉTICO CON OTROS CAMPOS TEÓRICOS Y PRÁCTICOS}

Deseamos indicar los nudos donde los distintos campos se tocan a fin de definir los diversos temas que una teoría o filosofía estética debería exponer.

De esta manera, en un primer intento de enfoque sistemático de una Estética de la Liberación, se manifiesta en la intersección de la estética con campos teóricos (como teorías). Será ingente la tarea futura de la producción de una nueva filosofía estética descolonizada, de una historia regional y mundial de la estética; como aísthesis (es decir, como subjetividad que elabora nuevos gustos y reglas para la interpretación estética) y como obras de arte (incluyendo también sus respectivas reglas, instrumentos, teorías de su producción, desarrollo de la crítica $^{57}$ estética tan esencial para el arte).

En un segundo nivel los cruces o articulaciones del campo estético con el campo técnico o productivo (como producción de la obra de arte) que depende en gran medida del avance civilizatorio de la cultura que produce obras de arte. Los instrumentos son necesario y no son iguales los instrumentos de madera que de bronce (en el tercer milenio a.C.) o que los de hierro desde su aparición. Hay entonces

57 Bien indica Walter Benjamin que la crítica, en un tercer nivel de la reflexión, e inspirándose en Fichte, realiza o corona a la obra de arte; sin crítica alguna queda inacabada, como acontece en la estética colonial, donde son hay va- una determinación técnica productiva inevitable lo que impide grandes obras de arte producidas con muy simples instrumentos (aunque con gran pericia). Las pirámides aztecas o egipcias -en este último caso tumbas-, muestran esos avances tecnológicos. Lo mismo que la literatura debió esperar hasta la escritura consonántica mesopotámica o alfabética para poder desplegar todo su esplendor. Lo mismo puede decirse de los instrumentos musicales, etcétera.

El tercer nivel es el cruce de la estética (esencial para una Estética de la Liberación) con los campos prácticos sean éticos, políticos, económicos, pedagógicos, de los géneros, las razas, etcétera. Todos los resultados de tales determinaciones deben ser consideradas como un proceso de la liberación de la aísthesis (en cuanto el asombro emotivo, sensibilidadinteligente ante la disponibilidad para la vida de las cosas reales son nuevamente juzgadas desde los criterios de la propia cultura, y no solo desde el eurocentrismo colonial estético), lo mismo que la autonomía en la producción de la obra de arte creando su reglas productivo-estéticas $y$ usando los instrumentos tradiciones que pueden, y en algunos casos deben ser desarrollados en diálogo con las otras culturas y la misma modernidad.

No será ya una mera producción de las obras de arte según la estética dominante del Norte. Como entre los Zapatistas el pueblo experimentará un renacimiento y reconocimiento de las estéticas del Sur, de-

loración ni crítica de las grandes obras de arte. La crítica realiza por último la obra de arte, porque le da su pleno sentido dentro del contexto de su propia cultura. Sin crítica de arte la obra desaparece como una gota de agua en el desierto. 
sarrolladas gracias a la creación de nuevas experiencias de la aísthesis y de nuevos estilos de las obras de arte liberadoras de la potentia de la belleza experimentada durante siglos (si no milenios) entre las culturas dominadas, los condenados de la tierra, los pueblos del Sur hoy en estado de renovación. 